\title{
Corticosteroids, Ornithine Decarboxylase Activity and the Incorporation of Leucine, Uridine, and Thymidine into Mouse Placenta
}

\author{
LESLEY M. TYE, J. F. RICHARDS, AND A. F. BURTON
}

Department of Biochemistry, University of British Columbia, Vancouver, British Columbia, Canada V6T IW5

\section{Summary}

The in vitro incorporation into mouse placenta of $\left[{ }^{14} \mathrm{C}\right]$ leucine, $\left[{ }^{3} \mathbf{H}\right]$ uridine, and $\left[{ }^{3} \mathbf{H}\right]$ thymidine fell between gestational days 14 and 19 by 61,30 , and $72 \%$, respectively; ornithine decarboxylase activity fell by $75 \%$. Injection of dexamethasone resulted on day 14 in values normally found between days 15 and 18 . These changes coincided with rising activity in fetal liver of the enzyme 11 $\beta$-hydroxysteroid:NADP oxidoreductase, which reduced the abundant 11-dehydrocorticosterone to the active hormone, corticosterone. These events appear to be part of a spectrum of effects produced by corticosteroids on fetal growth at this time, probably mediated primarily by fetal liver.
Speculation

The events induced by corticosteroids in placenta and brain involve changes in the enzyme which interconverts corticosterone and its inactive 11-dehydrometabolite. The same relationship has been reported between this enzyme and maturation of rat and rabbit lung, but at a later state of gestation. This suggests that regulation of these phenomena is not simply due to a rise in circulating hormone level, but involves enzyme activities in tissues which function to some extent independently. 


\section{Introduction}

Two recent reports have related effects of corticosteroids in fetal tissues to the enzyme which increases corticosterone by reduction of 11-dehydrocorticosterone. The latter is abundant in fetal tissues until late gestation, and reduction to the $11 \beta-0$ configuration increases the amount of active hormone at the expense of the inactive metabolite. Inhibition of this reaction lipid synthesis (5). Rising reductase activity in fetal mouse liver (3) coincided with a decrease in the dehydrogenation reaction in mouse brain, which was considered responsible for a marked decrease in the rate of incorporation of leucine, uridine and thymidine into fetal mouse brain (7). This communication describes similar effects in mouse placenta, indicating an action of corticosteroids on this tissue.

Materials and Methods

The mice used were of the UBC Swiss strain, raised at the zoology Department Vivarium at this University. The timing of pregnancies, the preparation and incubation of tissues and meas urement of incorporation of leucine- ${ }^{14} \mathrm{C}(\mathrm{U})$, uridine $-5^{3} \mathrm{H}$ and thymidine methy $1{ }^{3} \mathrm{H}$ into the acid-insoluble components of tissues have been described earlier (7). The preparation of 11-dehydro14 ricosterone-4- $c$ and incubation of it and corticosterone-4 been described therein. The assay for ornithine decarboxylase has been described elsewhere $(6)$.

Results

The reduction of ll-dehydrocorticosterone to corticosterone in fetal mouse liver and placenta on gestational days 14 and 17 s illustrated in Fig. 1. In similar experiments the dehydrogenation of corticosterone was also followed in these tissues. The ratio of reductase/dehydrogenase activity increased in liver from remained high at all times, the ratio was over 4

Table 1 gives the values for the incorporation of radioactive substrates into placenta on gestational days 14, 16 and 19. In all cases there was a significant decrease in the rate of ity began. This continued for several days with the greatest change between days 14 and 16 . The values for leucine, uridine and thymidine fell by 61,30 and $72 \%$, respectively, of those on and thymidine fell by 61,30 and $72 \%$, respectively, of those pattern (Table 1), declining by $75 \%$ on day 19. That these events can be attributed to the steroid is indicated by the fact that injection of dexamethasone on day 13.5 resulted in values on day 14 for all parameters which were
ally on days 15 to 18 (Table 1 ).

Microscopic examination of sections from treated placentas did not reveal any significant differences from controls.

Discussion

Until gestational day 14, 11-dehydrocorticosterone in fetoplacental tissues predominates over the active hormone by at least eightfold. This was attributed in earlier work (1) to dehydrogenase activity in fetal tissues and placenta. Subseto ascertain both dehydrogenase and reductase activities simultaneously, it was found that the ratio of reduction/dehydrogenation in placenta remains around 4 (Fig, 1), while the brain is the major site of dehydrogenation $(3,7)$. Conceivably the placenta functions to reduce the metabolite formed in fetal tissues before returning it to the maternal compartment. By contrast, reductase activity in fetal liver increased greatly, changing the ratio of reduction/dehydrogenation from 0.1 to 7 between days 14 and 17 . rt is probably this activity which is the major factor in raising lt is probably this activity which is the major factor in raising
corticosterone concentrations in the fetal circulation and in
blood entering the placenta from the fetus (3).

The presence of corticosteroid receptors in cytosol and nuclei of placenta has been reported (8), suggesting that this is a "target organ. The induction or specific biochemical to have been to have been reported previously. The decrease in the incorpis similar to that observed in fetal brain (7), also attributed is similar to that observed in fetal brain (7), also attributed to an increase in active corticosteroid. In both instances these events could be produced prematurely by the injection of pound was used in these experiments because it escapes to a large extent the metabolic regulation which limits the passage of hormone from mother to fetus, with the result that a more effective dose reaches the fetus (9). It was found that, 16 hours after injection, $6 \%$ of the dexamethasone remained in the maternal circulation. After 15 minutes, there was estimated (9) to be $60 \mathrm{ng} /$ $m g$
$(7)$ and in placenta ( likely that receptors were saturated and the effect of the dexamethasone maximal. While there was variation in the response, it should be pointed out that the stimulus here is being applied I to 2 days earlier than the rise in corticosteroid which occur
in the normal course of development, (3, Fig. 1) and this might modify the magnitude of the response in a tissue. In any case, all treated fetuses responded, with the values obtained being in
the range normally observed between gestational days 15 and 18 .

The decrease in ornithine decarboxylase activity parallelled that of thymidine incorporation in both placenta (Table l) and in fetal brain (7). Ornithine decarboxylase is an indicator of by hormones (6). A similar decline in thymidine kinase activity at this stage has been reported in rat placenta (6). These data suggest a decrease in the rate of several biosynthetic processes corticosteroid-induced maturation of fetal rabbit lung was accompanied by decreased growth and decreased cell division both in vivo (2) and in vitro (4). Normal maturation could be inhibited

Copyright (C) 1978 International Pediatric Research Foundation, Inc. $0031-3998 / 78 / 1211-1154 \$ 02.00 / 0$ activity in fetal rat lung (5). These events appear to be part mediated primarily by changes in the activity of the enzyme, $11 \mathrm{~B}$ mediated primarily by changes in the activity of the enzyme, 11Bferent tissues somewhat independently.

References

1. Burton, A.F. and Jeyes, C.L.: Corticosteroid metabolism in fetal and newborn mice. Can. J. Biochem. 46:15 (1968).

- Carson, S.H., Taeusch, H. W. and Avery, M. E.: Inhibition of rabbits. J. Appl. Physiol. 34: 660 (1973).

3. Michaud, N.J. and Buxton, A.F.: Maternal-fetal relationships in corticosteroid metabolism. Biol. Neonate 32: 132 (1977). different gestation-dopendent effects of cortisol on culdifferent gestation-dependent effects of cortisol on cul-

5. tured fetal lung cells. J. Clin. Invest. 53: 1518 (1974). tase activity in lung maturation in the fetal rat. Pediat.

Res. 12 : 12 (1978).

Thomson, M.J. and Richards, J.F.: Oxnithine decarboxylase treated rats: effect of hypophysectomy. Life. Sci. 22: 337 (1978).

7. Tye, L.M., Michaud, N.J. and Burton, A.F.: Corticosterone metabolism and the incorporation of leucine, uridine and

thymidine into fetal mouse brain. Submitted to Pediat. receptor complexes from mouse placenta. Can. J. Biochem. 52: 190 (1974)

9. Wong, M.D., Thomson, M.J. and Burton, A.F.: Metabolism of natural and synthetic corticosteroids in relation to thei effects on mouse fetuses. Biol. Neonate 28: 12 (1976).

10. Received for publication March 20,1978

11. Accepted for publication June 8, 1978 .

Table 1. Ornithine decarboxylase activity and the in vitro incorporation of ${ }^{14} \mathrm{C}-l$ leucine,
thymidine into mouse placenta.

\begin{tabular}{l|c|c|c|c}
\hline \multirow{2}{*}{$\begin{array}{c}\text { Gestational } \\
\text { Day }\end{array}$} & $\begin{array}{c}\text { Ornithine } \\
\text { decarboxylase, } \\
\text { pmoles } \begin{array}{c}2 \\
\mathrm{CO}_{2} / \mathrm{mg} \\
\text { protein }\end{array}\end{array}$ & \multicolumn{3}{|c|}{ Incorporation, dpm/mg protein of: } \\
\cline { 3 - 6 } & $13008 \pm 1491$ & $759 \pm 96$ & $1017 \pm 44$ & $1040 \pm 132$ \\
14 & $9243 \pm 562$ & $333 \pm 17$ & $633 \pm 83$ & $396 \pm 81$ \\
16 & $3179 \pm 609$ & $304 \pm 85$ & $713 \pm 89$ & $190 \pm 33$ \\
19 & $6170 \pm 1330$ & $465 \pm 40$ & $725 \pm 105$ & $641 \pm 55$ \\
\hline
\end{tabular}

*Dexamethasone, $200 \mu \mathrm{g}$, was injected subcutaneously $16 \mathrm{hr}$ earlier.

Ornithine decarboxylase activity was assayed by incubating the $20,000 \times \mathrm{g}$ supernatant of placenta with $50 \mathrm{nCi} /{ }^{4} \mathrm{C}-\mathrm{D}, \mathrm{L}-$ ornithine for $30 \mathrm{~min}$, following which ${ }^{1}{ }^{4} \mathrm{CO}_{2}$ was trapped in ${ }_{4} \mathrm{C}$ hyamine. ${ }^{1{ }^{4} \mathrm{C}-\text { leucine, } 0.14 \mu \mathrm{Ci},{ }^{3} \mathrm{H} \text {-uridine, } 0.46 \mu \mathrm{Ci} \text { and }{ }^{3} \mathrm{H}-}$ thymidine, $0.46 \mu \mathrm{Ci}$, were incubated in $1 \mathrm{ml}$ bicarbonate buffer $\mathrm{pH} 7.4$ for $1 \mathrm{hr}$. The tissue was then homogenized, an aliquot
removed for protein determination, and 0.1 vol $30 \%$ TCA was added. removed for protein determination, and 0.1 vol $30 \%$ TCA was added.
The precipitate was washed $4 \mathrm{x}$ with $3 \mathrm{~F}^{\circ} \mathrm{TCA}$ and then solubilized The precipitate was washed $4 \mathrm{x}$ with $3{ }^{\circ}$ TCA and then solubilized
and counted. Each figure is a mean \pm SEM of 4 to 7 values from and counted. Each figure is a mean \pm SEM of 4 to 7 values from day 16 , and the values on day 14 vs day $14+$ DEX are all signifday 16 , and the

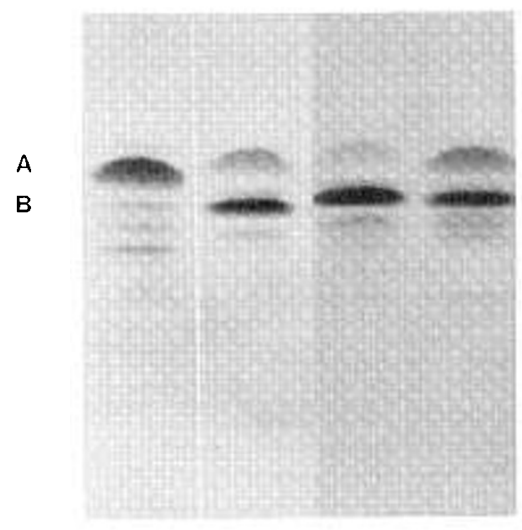

$\begin{array}{llll}1 & 2 & 3 & 4\end{array}$ Fig. 1. Autoradiograms of chromatographed extracts of mouse fetal
Iiver and placenta incubated with ${ }^{1} \mathrm{C}-11$-dehydro-corticosterone.

Livex from fetuses of a litter, or 2 placentas were minced finely and incubated in $1 \mathrm{ml}$ buffer $\mathrm{pH} 7.4$ with $5 \mathrm{nCi}{ }^{1{ }^{4} \mathrm{C}-11-}$ $\mathrm{CH}_{2} \mathrm{Cl}_{2}$ which was evaporated and spotted onto silica gel TLC sheets, developed in first, hexane: ethyl acetate (4:1) and sec-
ondly, toluene:chloroform:methanol: water (120:60:20:1; v:v) A: 11-dehydrocorticosterone; B: corticosterone. 1, fetal livex, day 14; 2 fetal liver day $17 ; 3$, placenta, day 14; 4 , placenta day 17 . Note the ind 